COMMISSION 5. DOCUMENTATION AND ASTRONOMICAL DATA

DOCUMENTATION ET DONNEES ASTRONOMIQUES

PRESIDENT: W.D. Heintz.

VICE-PRESIDENT: G.A. Wilkins.

ORGANIZING COMMITTEE: B.Hauck, J.Kleczek, P.Lantos, S.Mitton, J.-C.Pecker,

L. Schmade1, I. Shcherbina-Samojlova.

The range of activities of Commission 5 has considerably broadened over the last decade, compared with its originally bibliographical emphasis. This fact is a1so reflected in the new name of this Commission as adopted at the Montreal conference. The increased production of astronomical data, the growing role of data centers in the organisation and retrieval of information, as well as the editorial and bibliographic processing of the large number of primary papers have indicated the need for new and more efficient coordinative guidelines. Several documents have been published and are under consideration, or are in preparation, for the agenda at the IAU General Assembly in 1982.

B. Hauck is the IAU Representative on CODATA (ICSU Committee on Data for Science and Technology), with G.Wilkins representing the Federation of Astronomical and Geodetical Services (FAGS). Meetings of the ICSU Abstracting Board have been attended by L.Schmadel, P.Lantos, and W. Heintz, the latter also serving on the Executive Committee of the Board for the IAU term of office. S.Mitton succeeded J.Shakeshaft on the Organizing Committee of Commission 5.

Most of the activities are within the realms of the Working Groups on Astronomical Data (chaired by B.Hauck), on Classification Systems and Information Retrieval (P.Lantos), on Editorial Policy (S. Mitton), and the Special Working Group on the Designation of Astronomical Objects (W.Bidelman). Publications related to this work will be found primarily in the Bulletin d'information du Centre de Données Stellaires (Strasbourg, ed. C. Jaschek) and in the CODATA Bulletin.

IAU Colloquium no. 64 was held in Strasbourg on July $7-10,1981$ by Commission 5, the WG on Data, and the CDS, chaired by C. Jaschek. The title "Automated Data Retrieval in Astronomy" indicates its emphasis, a1though the spectrum of the more than fifty papers covered the efforts and problems in documentation more broadly. The proceedings are being prepared for publication in the Reidel series of IAU Colloquia.

The IAU has financially supported the publication of the revised index of catalogues under supervision by F.Spite; the work will be available shortly. Also supported was the new Multilingual Dictionary by J.Kleczek. The IAU Style Book, first published by J.-C.Pecker in 1966 (IAU Trans. XII C), and occasionally amended since, is undergoing a comprehensive revision by S.Mitton in consultation with the IAU. Under consideration is the addition of editorial guidelines, the irclusion of which has repeatedly been suggested. The Guide to the Presentation of Data, prepared by G. Wilkins along CODATA procedures, and already discussed in Montreal, has been redrafted, and received further discussion among Commission 5 members at the occasion of the Strasbourg meeting, before it was sent to other IAU Commissions for final comments preceding action at the next IAU Assembly. G. Wilkins has also prepared a Proposal for Glossary of Terms Relating to the Storage, Retrieva1 and Analysis of Astronomica1 Data (Bulletin CDS 21, 47-49).

The following Progress Reports (in continuation of those in IAU Trans. XVII A, pt. 1, p.7) have been received. 
Working Group on Astronomical Data (Report for the period 1979-81 by B.Hauck):

The main activity of our WG was devoted to trying to centralize the information concerning the astronomical plate vaults. An inquiry of a large number of observatories revealed that the majority of people concerned are in favour of such centralisation. The CDS at Strasbourg has agreed to act as centralizer. Details concerning this action will be published in the proceedings of the IAU Colloquium No. 64 .

Our WG was also interested in the Flexible Image Transport System (FITS, see D. C.Wells et al., A.A.Supp1. 44, 363; E.W.Greisen and R.H.Harten, A.A.Supp1. 44, 371,1981 ) and will support this very valuable solution for the exchange of data.

During the period covered by this report we have seen the development of astronomical data networks: STARLINK in the U.K., ASTRONET in Italy, and another one in Japan. The development of stellar data centers is encouraging and the fact of having such centers in France, USA, USSR, Japan and the DDR facilitates the access to astronomical data. The most important developments in this field are definitely the Catalogue of Stellar Identification (F. Ochsenbein et al., 1981, A. A. Suppl. 43, 259) at the CDS, Strasbourg, and the Infrared Data Base at the GSFC, Greenbelt, Maryland (see D.Schmitz et al., 1981, Astron. Data Center Bu11. 1, 94).

CODATA's scientific conference was held at Kyoto (October 8-11, 1980). The proceedings of this conference are now available (Ph.Glaeser, Data for Science and Technology, Pergamon Press, 1981).

\section{P. Lantos):}

Working Group on Classification Systems and Information Retrieval (Report by

Le travail du groupe de travail s'est centré sur le souhait de la Commission 5 durant $1^{\prime}$ Assemblée Générale de $1^{\prime}$ U.A.I. de Montreal de voir preparer un vocabulaire d'Astronomie qui puisse être utilisé par les auteurs pour indexer leurs propres articles scientifiques.

Le WG se compose de R. Bensaid (France), Mme C.Bérardini (France), M.J.Co11ins (U.K.), P.Lantos (chairman; France), L.D.Schmadel (BRD), S. Schiminovich (USA), and G.A.Wilkins (U.K.). Il s'est réuni une premiere fois a Strasbourg en Juillet 1981 . Une version de travail du vocabulaire a été crée sur le principe d'une compatibilité avec les listes de mots clefs déjà existentes qu'elles proviennent des services bibliographiques (comme le AAA vocabulary) ou des revues primaires (Astrophys.J., Astr.Astrophys.) qui s'en servent pour leur index annuel. Il a semblé souhaitable que ce vocabulaire soit aussi compatible avec la classification décimale universelle (Federation Internationale de Documentation) et avec la classification de Physique mise au point dans le cadre de 1'ICSU AB. Cette classification internationale est en effet adoptee par la majorite des services publiant des revues bibliographiques: AIP (USA), INSPEC (UK), CNRS (France), Physikalische Berichte (BRD).

Le vocabulaire contient environ 1000 mots clefs. Il sera soumis a des experts de chaque discipline de $1^{\prime}$ Astronomie et de l'Astrophysique et une réunion du Working Group est prevue pour le printemps 1982 afin de confronter les points de vue. Si un accord est obtenue, le vocabulaire UAI pourra être présenté a la Commission 5 lors de Assemblée Générale de Patras durant 1'été 1982.

Special Working Group on Designation of Astronomical Objects (W.Bidelman):

Following the suggestion by Commission 5 to allow further discussion of the matter on hand, the entire Report of this WG has been published in Bulletin CDS 18, p.44, 1980, including the full text of the recommendations (which are modified slightly in form from those printed in IAU Trans. XVII B, p. 87). It is urged that 
interested colleagues consult this paper and submit comments before report and recommendations will be moved for adoption by the entire Commission and by the IAU EC in Patras. With this task discharged, the Commission should also consider at that time whether the Working Subgroup be disbanded, or be reconstituted for work on farther-reaching, related problems.

Activity in Astronomical Documentation in the USSR (Report for the period 1978-80 by I.S. Shcherbina-Samojlova, Head of the Astronomy and Geodesy Department, VINITI, Moscou):

1. The Astronomy and Geodesy Department of VINITI (A11-Union Institute for Scientific and Technological Information) continued publication of subjects 51 (Astronomy), 62 (Space Research), and 52 (Geodesy and Aerial Surveying) of the Referativnyi zhurnal. The number of abstracts totalled 20,000 annually in three issues.

2. New volumes in the series Itogi Nauki (state-of-the-art reviews) are:

Series Astronomy: 1978, vol.14, Solar Physics.

1979, vol.15, Asteroids: Origin, Statistics, Evolution.

1980, vol.16, Radio exploration of the Moon and the terrestrial planets.

Series Space Research: 1978, vol. 11, Some problems of Satellite Orientation.

1978, vol.12, Cosmic Rays of Solar Origin.

1979, vol.13, Solar Arrays under Influence of Solar Radiation.

1979, vol.14, Astronomy of Infrared and Sub-mm Range.

1980, vol.15, Earth's Artificial Satellite Motions.

1980, vol.16, Methods and Possibilities of Remote Sensing.

3. "Soviet Astronomy Bibliography for 20 years (1958-1977)" and "Annotating Index on the Moon and Related Investigations (1968-1980)" have been prepared for publication; the production of these volumes is delayed.

4. A collection of papers entitled "Informatics in Astronomy and Geodesy" is in press. (Abstracts of the papers have been sent to Commission 5.)

5. Work toward improvement of UDC 52 (Astronomy) continued, in particular, the following section proposals have been prepared:

523.9. The Sun. Solar Physics (jointly by the Natural Sciences Library, the Institute for the study of Geomagnetism, Ionosphere, and Radiowave Propagation, both of the Akademia Nauk USSR, and VINITI);

523.4. Stars (by VINITI and the Sternberg Astronomica1 Institute).

6. VINITI and the Astronomical Observatory of Kharkow University constructed an Accordance Table between UDC 52 and the Rubricator of the Referativnyi Zhurna1 Astronomy. This document will be distributed for use in all astronomical institutes and editorial offices, since the UDC is the official classification system of all scientific and technical publications printed in the USSR.

7. Compilation of a thesaurus of astronomical terminology was continued for future use in automatic information retrieval.

8. The following papers were published:

T. I.Zapolskaya, I.S. Shcherbina-Samojlova, Selected Results from a Study of Astronomy Document Flow, with special reference to the Astronomy Abstract Journal; Nauchno-Techniceskaya Informatsiya (NTI), ser.I, no.9, 21-26. (Scientific and Technical Serial of VINITI, Moscou).

I.S. Shcherbina-Samojlova, V.T.Fedorov, Primary and Secondary Journals in Radio Astronomy; NTI ser.I, no.1, 23-27, 1979.

T.I.Zapolskaya, I.S.Shcherbina-Samojlova, Analysis of Information Flow Dynamics as a Method of Studying the Development of Astronomy and its Sections. 
NTI ser.I, no.9, 23-30, 1979.

T. I.Zapolskaya, G.S. Shvedova, I.S. Shcherbina-Samojlova, Information Supply to the Specialists of Astronomical observatories (with the example of the Special Astropysical Observatory of the USSR Akademia Nauk; NTI ser.I, no.12, 11-12, 1980.

V.T.Fedorov, The Basic Elements of Scientific Publications and their Analysis;

Radiophysical Institute in Gor'kij, Preprint no.135, 1980.

other Abstracting Services in Astronomy and related fields: The latest reports have been presented at the meeting of the Abstracting Board in Pine Mountain (Georgia) in May 1981.

Star catalogs and files available at the Stellar Data Center (Strasbourg): The Bulletin CDS 21, 52 - 117 provides a new, cumulative Iisting which supersedes previous lists.

W. D. HEINTZ

President of the Commission. 